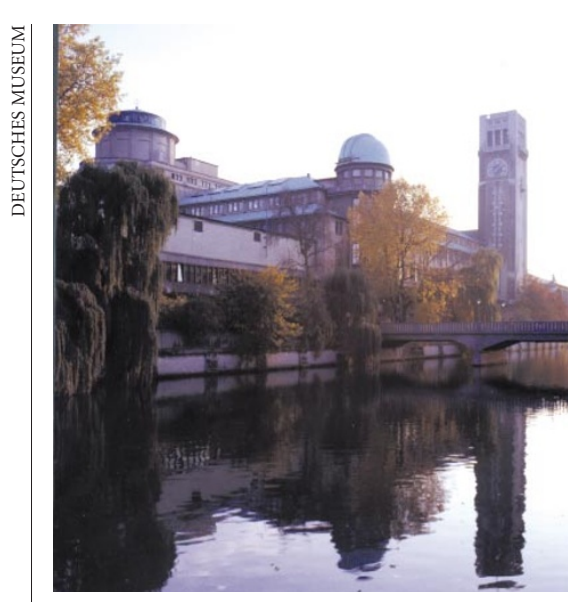

Shrinking asset: Munich’s Deutsches Museum.

increased next year. But the science museums are not being exempted from an overall decrease of DM30 billion ( $\$ 16$ million) in public spending imposed by finance minister Hans Eichel to reduce the national debt.

"This is a clear [act of] discrimination against the WGL, and science museums in particular," says an official of the Bund-Länder-Kommission für Bildungsplanung und Forschungsförderung (BLK), which coordinates regional and federal research policies.

The WGL already faces the problem that responsibility for funding its institutes is spread over ten ministries. As for the science museums, funding responsibility shifted last year from the Ministry of the Interior to the new Ministry of Cultural and Media Affairs.

Culture minister Michael Naumann has announced that the cuts will be imposed equally across all spending areas of his ministry. With a relatively small portfolio of DM1.7 billion, Naumann says that he cannot prioritize some areas by excluding them from the cuts. In contrast, the research ministry has been able to respond more flexibly by shifting its priorities.

Research costing DM46.2 million is being carried out at the six science museums this year. Germany's science council, the Wissenschaftsrat, has confirmed the high quality of the museums' research departments, and recommended that the proportion of research to other museum activities should be maintained.

But the 7.5 per cent cut will hit the museums hard. "The cuts come at a time when we had been about to expand our activities," says Helmuth Trischler, director of science and vice-directorgeneral of the Deutsches Museum. "As a consequence, we will not be able to do what we intended to." Quirin Schiermeier

\title{
US university finds use for Air Force research reactor
}

\section{San Diego}

The University of California (UC) at Davis received approval last week to acquire a research nuclear reactor, up to now used by the US Air Force (USAF), for use in studies in engineering, materials science, agriculture and medical therapies.

The reactor, located at the USAF's McClellan Air Force Base, about 20 miles from the university, was built in 1990, making it the youngest of the TRIGA (Training, Research, Isotopes, General Atomics) class of research reactors which are no longer being built in the United States.

The reactor will form the core of a developing research programme at Davis, which officials say will become more important in future years as older research reactors are decommissioned and not replaced.

"Eventually, UC Davis may be the only show around" for research reactors, says Kevin M. Smith, UC Davis' vice-chancellor for research. Officials say that research reactors are difficult to build because of increasing costs, the extensive environmental assessment process required and community opposition.

Under terms of the agreement approved last week by the UC Board of Regents, the reactor must be used at least 51 per cent of the time for research; the remainder of the time it can be used for revenue-producing commercial work, which university officials hope will cover some of its operational costs.

The Air Force has been using the reactor for neutron radiography to detect hidden cracks and defects in aircraft wings. Some similar work may continue as UC Davis builds up its reactor-based research programme.

After a competitive selection process, the university has appointed Science Applications International Corp. (SAIC) of San Diego as the reactor's operator. Most employees now working at the site will be hired by SAIC.

The US Department of Energy is providing $\$ 8$ million to fund research and operational costs for the reactor for the next four years. And the federal government is giving \$17.6 million for the future decommissioning of the reactor, expected in about 30 years.

As UC Davis develops a programme of teaching and research around its reactor, officials plan to collaborate with UC Berkeley's department of nuclear engineering, and with UC Irvine.

Rex Dalton

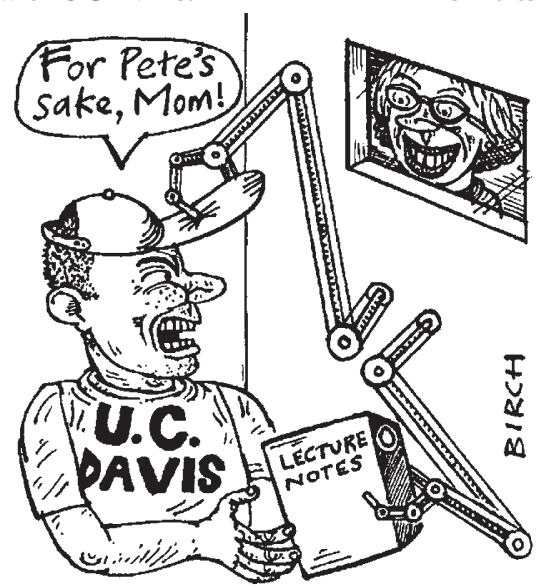

\section{UK universities look to enterprise}

\section{Sheffield}

Eight UK universities are to set up 'centres of enterprise' to exploit their research and transfer ideas to the private sector. Steven Byers, the Secretary of State for Trade and Industry, announced the news last week at the British Association for the Advancement of Science's annual Festival of Science.

One of the responsibilities of the centres,

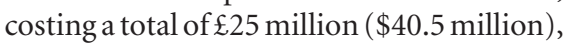
will be to incorporate the teaching of enterprise into the universities' curricula, equipping scientists and engineers with entrepreneurial skills. The government hopes the centres will play a key role in regional development, and wants them to link up with local companies.

Byers also announced the extension of the network of Faraday Partnerships, which aim to link science and business in specific areas of technology by bringing together consortia of independent research organizations, universities, businesses and financiers. Four new partnerships, with a budget of $\mathfrak{E} 8.8$ million, were announced. Consortia are invited to propose new topics in their bids. "We want your ideas, we want to see partnerships strengthening industry clusters in their localities," said Byers.

Byers announced additional funding for the four existing Faraday Partnerships. He said this was because the previous government had underfunded the centres, and added that the extra support would allow them to restructure their 'industry-facing' activities.
NatashaLoder 